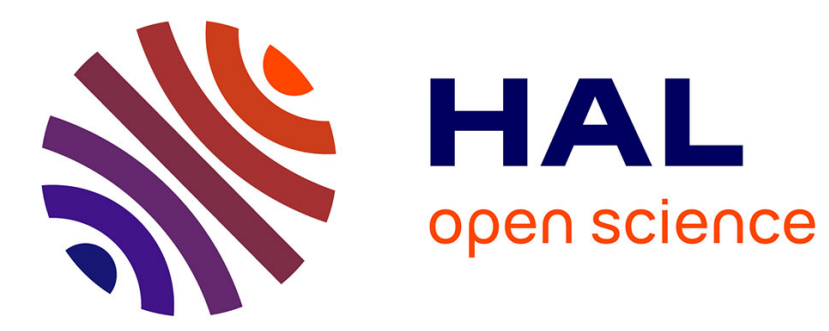

\title{
Metallic nanoparticles growth on ionic layer grafted onto glassy carbon for hydrogen evolution reaction
}

Selma Bencherif, Mourad Mechouet, Jalal Ghilane

\section{To cite this version:}

Selma Bencherif, Mourad Mechouet, Jalal Ghilane. Metallic nanoparticles growth on ionic layer grafted onto glassy carbon for hydrogen evolution reaction. Journal of Molecular Liquids, 2021, 341, pp.117433. 10.1016/j.molliq.2021.117433 . hal-03341952

\section{HAL Id: hal-03341952 \\ https://hal.science/hal-03341952}

Submitted on 13 Sep 2021

HAL is a multi-disciplinary open access archive for the deposit and dissemination of scientific research documents, whether they are published or not. The documents may come from teaching and research institutions in France or abroad, or from public or private research centers.
L'archive ouverte pluridisciplinaire HAL, est destinée au dépôt et à la diffusion de documents scientifiques de niveau recherche, publiés ou non, émanant des établissements d'enseignement et de recherche français ou étrangers, des laboratoires publics ou privés. 
Metallic nanoparticles growth on ionic layer grafted onto glassy carbon for hydrogen evolution reaction

Selma Bencherif ${ }^{1,2}$, Mourad Mechouet ${ }^{2}$, Jalal Ghilane ${ }^{1 *}$

1. Université de Paris, ITODYS, CNRS, UMR 7086, 15 rue J-A de Bä̈f, F-75013, Paris, France

2. University of Mouloud Mammeri, Tizi-Ouzou, Department of chemistry, Algeria

\section{Abstract}

The present work reports the immobilization of thin ionic layer onto glassy carbon and its use as a platform for the electrochemical growth of metallic nanoparticles. The ionic layer was electrochemically grafted during the reduction of the in situ generated diazonium bearing imidazolium, 1-nitrophenylethyl 3-methylimidazolium bis(trifluoromethyl- sulfonyl)imide. Next, the metallic nanoparticles, platinum or palladium, were electrochemically grown onto the ionic layer modified electrodes. The physico-chemical properties of the generated modified electrodes were studied by surfaces analysis and electrochemical methods. Furthermore, the electron transfer properties of the modified electrodes were investigated at the local scale using scanning electrochemical microscope (SECM). The obtained results confirm the success of the ionic layer grafting as well as the formation of the metallic nanoparticles. The SECM investigations display change in the electron transfer properties of the modified electrodes depending on the used redox mediator. Finally, the as-prepared modified electrodes catalytic performances of towards the hydrogen evolution reaction (HER) were evaluated. Interestingly, the presence of the ionic layer displays an increase of the catalytic performances, for both investigated metallic nanoparticles. This behavior is probably due to the existence of synergistic effect between the grafted ionic layer and the metallic nanoparticles. Therefore, it is anticipated that the ionic layer immobilization had several features including the tuning of the electrode interface properties, acting as a platform and binder for the nanoparticles growth as well as the enhancement of the electrocatalytic performances. 
Keywords: Surface modification, ionic organic layer, scanning electrochemical microscope, electrocatalysis, hydrogen evolution reaction (HER).

\section{Introduction}

Surface chemistry offers an elegant approach to tune the materials properties. Within this expanding field, several approaches were described leading to the anchoring various functional molecules onto different materials [1]. Electrochemistry assisted grafting methods were reported to be an efficient process for the immobilization of thin organic layers, few nm thick, onto different support including metals, carbon, semiconductor and nanomaterials [2]. Electrochemical reduction of diazonium derivatives is, by far, the widely used method for producing a covalent attachment of thin organic layers onto electrodes materials [3]. Several diazonium derivatives have been studied leading to decorate the surface with the desired functional groups that could be tailored according to the targeted applications. This approach became a significant for many applications such as energy storage, separation technologies, sensors and molecular electronic devices [4-6] Besides that, ionic liquids (ILs) become a very attractive scientific field due to their interesting physicochemical properties [7]. Recently, the immobilization of molecules based on ionic liquids have been studied providing to the interface some of its properties [8,9]. This approach became a significant part appeared in the literature and exhibits an interesting strategy to overcome some limitations related to the use of ionic liquids at the industrial scale including the high viscosity and cost, toxicity as well as the reduction of used ionic liquids amount. Several reported works highlight the potential applications of immobilized ionic liquids, onto different supports, in energy storage and conversion, and smart materials [10-12]. The attachment of molecules containing ionic liquid framework have been performed using various methods, including simple physisorption, self-assembly, polymerization and the electrochemical grafting process $[13,14]$. Several substrates were used for the electrochemical assisted surface modification including carbon based materials $[15,16]$. The glassy carbon (GC) is inert material and dis- 
plays a weak activity towards the electrochemical activation of small molecules including hydrogen evolution reaction, which make it a material of choice as a support electrode in electrocatalysis. However, modulating the properties of carbon electrode interface through the electrochemical grafting has not been extensively used in the electrocatalysis field. Thus, surface modification of carbon electrode could be employed as a promising approach to make the interface suitable for the metallic nanomaterials growth and/or favorable for the electrocatalytic reaction.

In this work, the electrochemical grafting of molecule containing the ionic liquid framework, onto GC electrode was performed. As a result, an ionic thin layer containing the immobilized imidazolium cation and labile anion is generated onto the electrode surface. Next, the as-prepared layer is used as a platform to perform the electrochemical growth of platinum or palladium nanomaterials. The generated modified surfaces were characterized using electrochemical and surface analysis methods. In addition, the electron transfer properties of the different modified surfaces were investigated, at the local scale, using SECM. Finally, the electrocatalytic properties of the modified electrodes towards the hydrogen evolution reaction were studied.

\section{Experimental section}

\subsection{Chemicals}

1-nitrophenylethyl 3-methylimidazolium bis(trifluoromethyl-sulfonyl)imide was synthesized using the previously reported procedure [17]. For the metal electrochemical deposition $\mathrm{Na}_{2} \mathrm{PdCl}_{4}$ and $\mathrm{K}_{2} \mathrm{PtCl}_{4}$ (supplied from Sigma Aldrich) were used as received. Ferrocene and potassium hexacyanoferrate(II) $\mathrm{K}_{4} \mathrm{Fe}(\mathrm{CN})_{6}$ (from Aldrich) were used as redox mediators. All the used chemicals were purchased at the highest available purity.

2.2 Surface characterization X-ray photoelectron spectroscopy (XPS) measurements were performed using a Thermo VG Scientific ESCALAB 250 system fitted with a micro focused, monochromatic Al KR $(\mathrm{h} v=1486.6 \mathrm{eV}) 200 \mathrm{~W}$ X-ray source. 
2.2 Electrochemical measurements The electrochemical analyses were performed using a conventional three-electrode cell and the measurements were performed on CHI660C potentiostat ${ }^{\circledR}(\mathrm{CH}$ Instruments, Austin, Texas). A graphite rod and $\mathrm{Ag} / \mathrm{AgCl}$ are used as auxiliary and reference electrodes, respectively. Glassy carbon (GC) (3 mm diameter) was used as a working electrode. Before each electrochemical acquisition, the solution was deoxygenated by bubbling argon gas and was kept during the experiment. For SECM studies, $\mathrm{Ag} / \mathrm{AgCl}$ and platinum wires were used as a reference electrode (RE) and counter electrode (CE), respectively. A Pt ultramicroelectrode (UME) with a diameter of $10 \mu \mathrm{m}$ was employed as working electrode. The obtained SECM data were plotted as the normalized current versus the normalized distance $L=d / a$, where " $d$ " is the gap between the tip and the substrate and " $a$ " is the tip radius ${ }^{11}$. The used SECM instrument in this study is CHI 900B (CH Instrument, Austin, TX), with close-loop piezoelectric motors.

\section{Results and discussion}

\subsection{Surface functionalization}

For this purpose, the 1-nitrophenylethyl 3-methylimidazolium bis(trifluoromethyl- sulfonyl)imide, $\left[\mathrm{NO}_{2}\right.$-phenylIm] [TFSI], electrografting on glassy carbons (GC) was achieved, according to the previously reported procedure [17]. Briefly, the [ $\mathrm{NO}_{2}$-phenyl-Im] was reduced in acidic media leading to the formation of the corresponding amino compound. Next, by diazotation reaction mean, this compound is converted to the corresponding diazonium, which is generated exclusively within the diffusion layer and then reduced to generate the corresponding radical, the latter reacts with the carbon surface leading to its attachment as illustrated in Scheme 1a. 


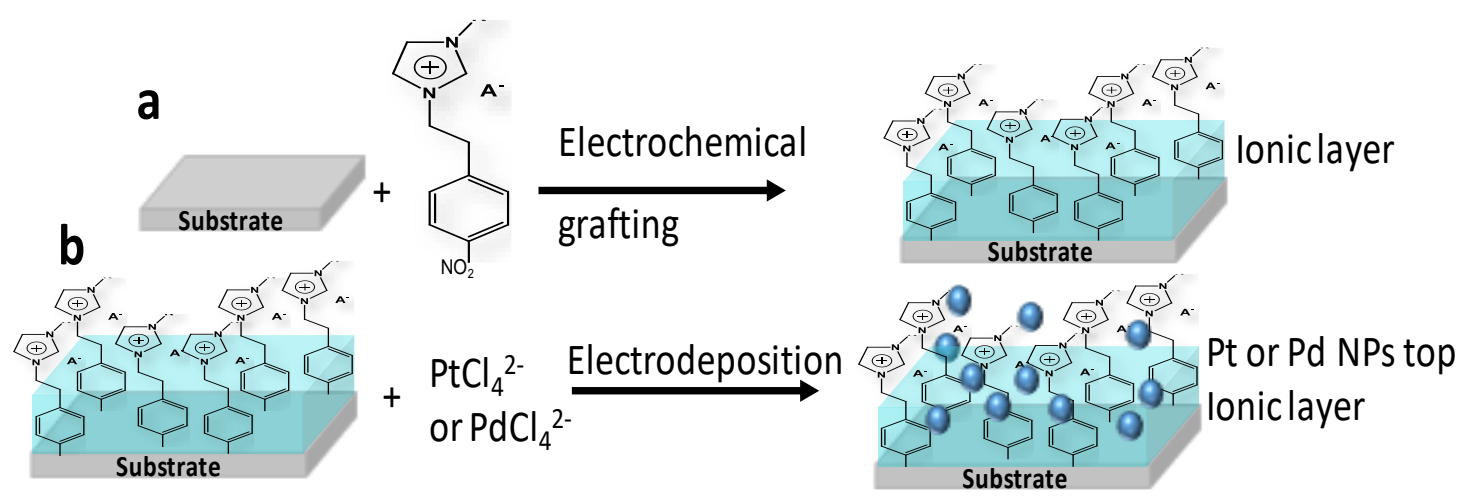

Scheme 1. (a) Immobilization of [Phenyl-Im][A-] onto glassy carbon electrode surface via electrochemical grafting of the corresponding diazonium. (b) Electrochemical deposition of Pt ot Pd onto GC/IL.

In a second step, the attached ionic layer will be used as a platform for further functionalization using metallic nanoparticles electrochemical growth as shown in Scheme 1b. This approach will lead to generate hybrid materials containing organic layer and metallic nanoparticles.

The surface chemical composition was characterized by X-ray photoelectron spectroscopy (XPS). Fig. 1 shows the high resolution XPS spectra of $\mathrm{C} 1 \mathrm{~s}$ and N1s recorded on the ionic layer attached onto glassy carbon electrode, GC/IL.
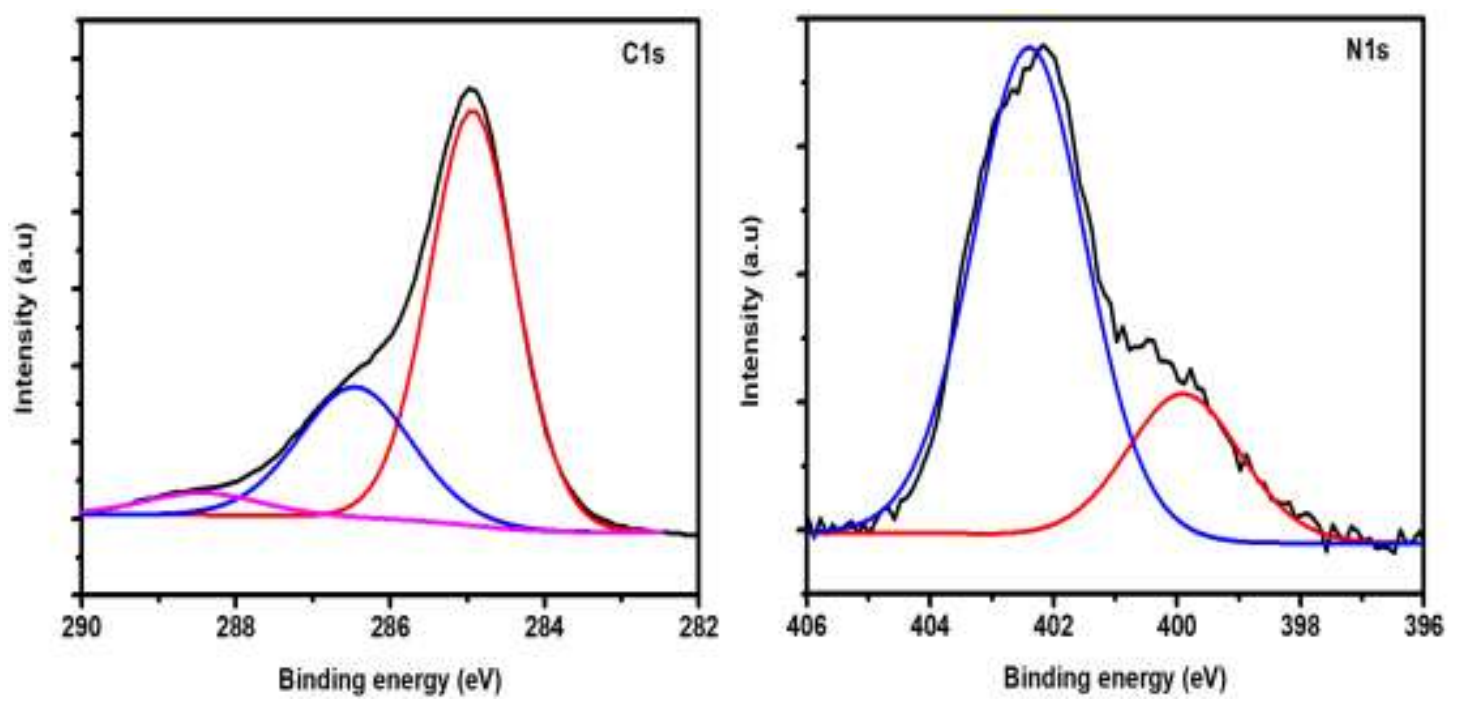

Fig. 1. XPS High resolution spectra of C(1s) and N(1s) elements of GC/IL modified electrode. 
The C1s spectrum (Fig.1a) can be deconvoluted into three components. The peaks observed at 285 and $286.5 \mathrm{eV}$ correspond to $\mathrm{C}-\mathrm{C}$ and $\mathrm{C}=\mathrm{N}$ groups, respectively. These functions confirm the presence of imidazolium ring $[14,16]$. Next, a minor peak is observed at $288.5 \mathrm{eV}$ and attributed to COO, resulting from the surface contamination. Besides that, the N 1s spectra (Fig.1b) displays a main peak located at 402.5 $\mathrm{eV}$, which is attributed to imines group in the imidazolium ring and a minor peak at $399.5 \mathrm{eV}$, originated from surface contamination $[18,19]$. In addition, the XPS investigations show the presence of signal corresponding to F1s and S2p demonstrating the presence of the ionic liquid anion [TFSI] within the attached layer. All these results confirm the success of the electrochemical grafting of the ionic layer at the GC electrode surface.

Post-functionalization is another approach leading to enhance the panel of surface modification and to decorate the previously modified electrode surface. For this purpose, several strategies were reported including chemical surface reaction, i.e. peptide coupling, Gomberg-Bachmann coupling and click chemistry, and electrochemical deposition [18,20-22]. In this work, the GC/IL modified electrode was used as working electrode for further functionalization using electrochemical deposition of platinum or palladium. The GC/IL was immersed in aqueous electrolytic solution containing $10^{-3} \mathrm{~mol} / \mathrm{L}$ of $\mathrm{K}_{4} \mathrm{PtCl}_{4}$ or $\mathrm{K}_{4} \mathrm{PdCl}_{4}$ and the deposition was performed by chronoamperometry. Several reductive potentials, ranged from -0.1 to $-0.6 \mathrm{~V} / \mathrm{Ag} / \mathrm{AgCl}$, were investigated to produce the GC/IL/Pt and GC/IL/Pd. The generated modified surfaces were characterized by XPS analyses. The results display the presence of C1s and N1s elements, similarly to the results shown in Fig 1, indicating the presence of the ionic layer despite the further metal electrochemical deposition. 

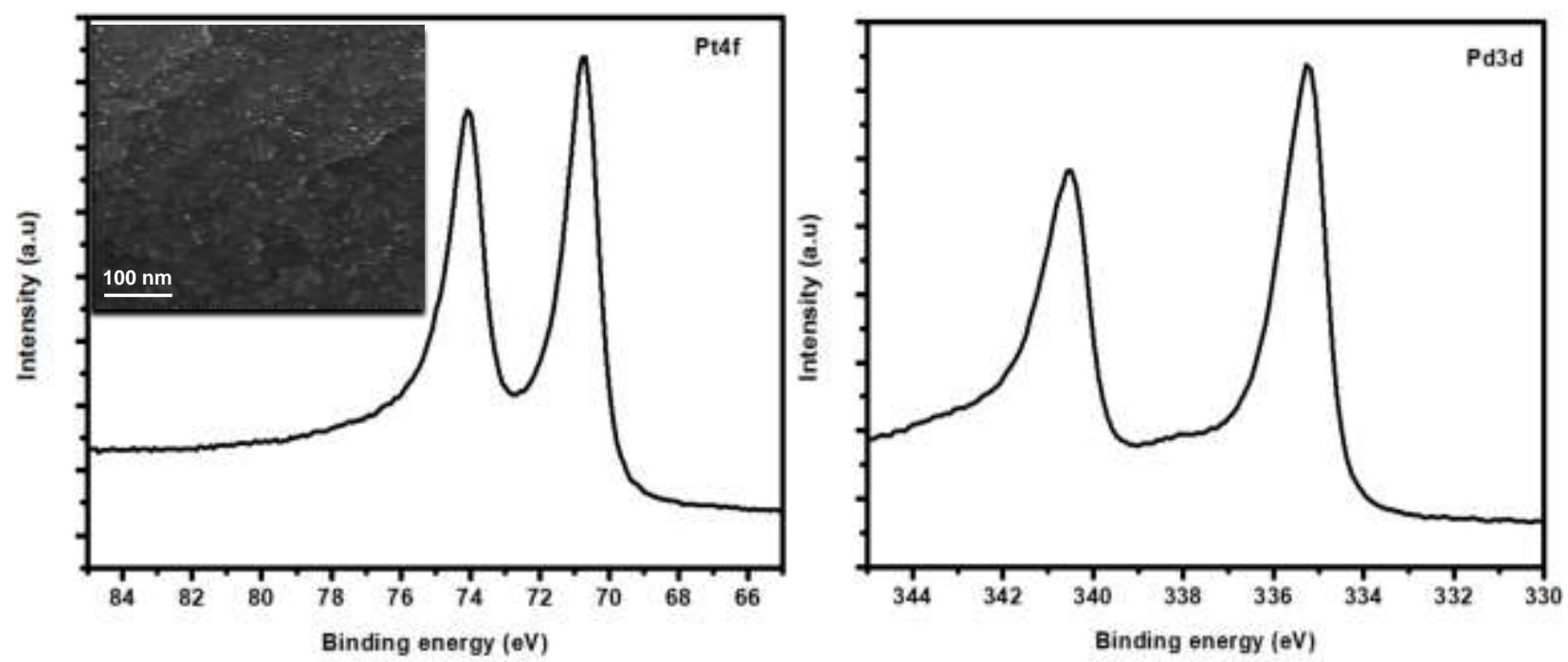

Fig. 2. a) XPS high resolution spectra of $\mathrm{Pt}(4 \mathrm{f})$ and $\mathrm{Pd}(3 \mathrm{~d})$ recorded on GC/IL/Pt and GC/IL/Pd. Inset shows the SEM image recorded on GC/IL/Pt.

The XPS studies recorded on GC/IL/Pt reveal two major peaks located at 71 and $74.2 \mathrm{eV}$, which can be assigned to the $\mathrm{Pt} 4 \mathrm{f}_{7 / 2}$ and $\mathrm{Pt} 4 \mathrm{f}_{5 / 2}$, respectively and correspond to the metallic $\mathrm{Pt}$ [23]. The absence of peaks at higher binding energy, at 72 and $77 \mathrm{eV}$, confirms the absence of Pt oxide. the In the case of Pd electrodeposition, the XPS spectrum shows two peaks located at $335.2 \mathrm{eV}$ and $341 \mathrm{eV}$ attributed, respectively, to the $\operatorname{Pd} 3 d_{5 / 2}$ and $\operatorname{Pd} 3 d_{3 / 2}$ spin orbit states of metallic $\operatorname{Pd}(0)$, Fig $2 b$ [24]. Overall, the XPS analyses confirm the ionic layer grafting onto glassy carbon electrode and the success of the metal electrochemical deposition and thus generating hybrid electrode, GC/IL/NP. The SEM image performed on GC/IL/Pt sample displays the presence of bright spot corresponding to metallic platinum. Besides that, the image shows a homogeneous nanoparticles distribution onto the GC/IL modified electrode with an average size around $10 \mathrm{~nm}$. In the absence of the ionic layer, the SEM images of GC/Pt sample display less homogeneous particles distribution and higher particles size (around $50 \mathrm{~nm}$ ). This result suggests the difference on the nucleation growth process of Pt NP's deposited onto GC or on GC/IL.

\subsection{Local electrochemical investigation using SECM}


The electron transfer properties, at the local scale, of the generated electrodes were investigated using scanning electrochemical microscopy (SECM). SECM is a powerful technique to probe the electrochemical reactivity at a given surface. The method leads to investigate a surface from the solution side thanks to the use of an ultramicroelectrode, UME, and the appropriate redox couple [25]. In addition, the method permits the analysis of the modified surfaces at their open circuit potential (unbiased substrate). Briefly, a redox mediator is oxidized or reduced at the UME, under diffusion control, and the UME potential was kept at a potential where the steady-state current is established. Next, the UME was brought to the investigated substrate while recording the current variation as a function of the UME/substrate distance. During this approach, the UME current variation depends on the electrochemical reactivity of the probed surface and the electrochemical reaction loop within the gap UME/substrate. In the literature, the SECM has been used for the investigation of modified surfaces and leads to bring a new insight on the charge transfer properties at the modified surface [26-28]. Fig. 3a illustrates the SECM configuration for the investigation of different modified electrodes (GC/IL and GC/IL/Pt).
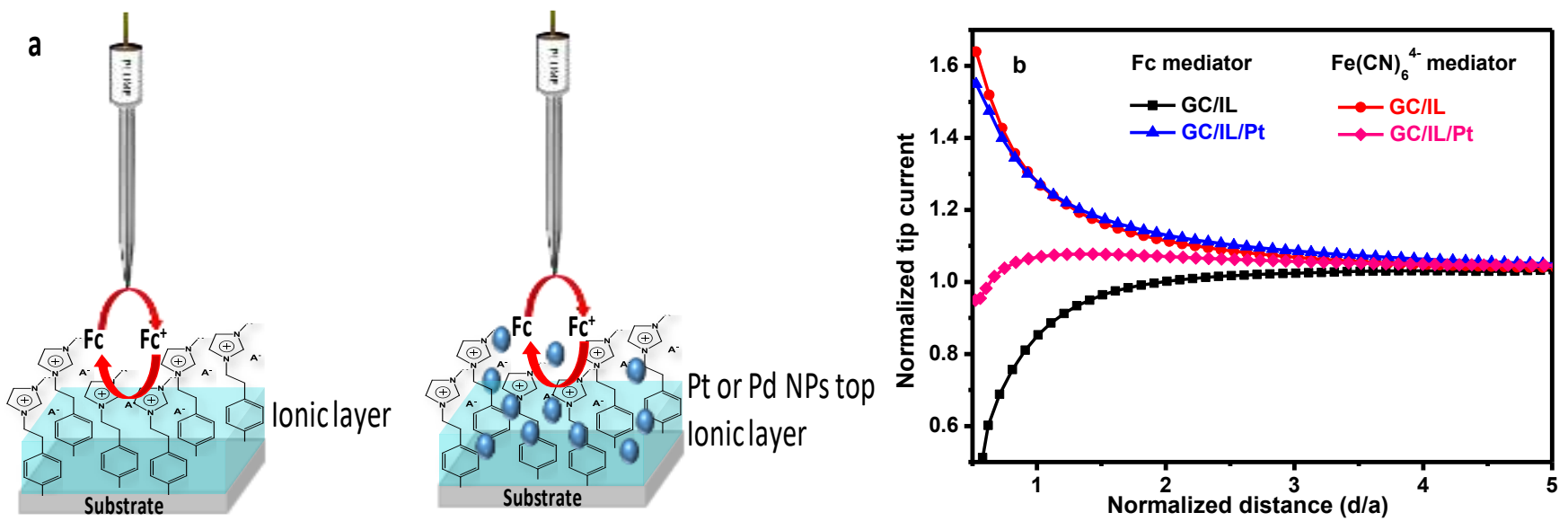

Fig. 3. SECM approach curves on a surface GC/IL/Fe, GC/IL/NPs in ACN solution containing $0.001 \mathrm{~mol} / \mathrm{L}$ of Ferrocene $+0.1 \mathrm{~mol} / \mathrm{L} \mathrm{Bu}_{4} \mathrm{NBF}_{4}$ and in aqueous $\mathrm{KCl}$ solution containing $0.001 \mathrm{~mol} / \mathrm{L}$ $\mathrm{K}_{4} \mathrm{Fe}(\mathrm{CN})_{6}$

Fig. $3 b$ depicts the approaches curves recorded on GC/IL and GC/IL/Pt surfaces using two redox mediators, namely the ferrocene $(F c)$ and ferrocyanide $F e(C N)_{6}^{4-}$. These redox probes were selected since they present different oxidation state as well as electron transfer process (outer-sphere for $F c$ and an inner- 
sphere for ferricyanide). In the case of GC/IL modified electrode, the recorded approach curves with Fc and ferrocyanide display different shape. For Fc redox probe (black curve), the UME current decreases when the UME is approaching the substrate indicating that the backward reaction $\left(\mathrm{Fc}^{+}+\mathrm{e}^{-} \rightarrow \mathrm{Fc}\right)$ is not take place at the substrate or occurs with a low electron transfer. This behavior suggests that the GC/IL act as a barrier against the electron transfer. The curve fitting leads to estimate the apparent electron transfer rate $\left(\mathrm{k}_{\mathrm{app}}\right)$, which is found to be around $10^{-4} \mathrm{~cm} \cdot \mathrm{s}^{-1}$ [29]. This low value confirms the presence of slow electron transfer process and thus the regeneration of $\mathrm{Fc}$ is hundred by the ionic layer which acts as a barrier against the electron transfer. Such behavior could be explained by the presence of ionic layer with a thickness higher than $5 \mathrm{~nm}$ (tunneling distance) or the presence of electrostatic repulsion between the generated $\mathrm{Fc}^{+}$, at the UME, and the attached imidazolium. In the case of ferrocyanide as redox probe, the approach curve exhibits a current enhancement (red curve) suggesting the generation of the redox probe at the GC/IL surface with an apparent electron transfer rate constant around $2 \times 10^{-2} \mathrm{~cm} \cdot \mathrm{s}^{-1}$. This behavior was unexpected since the ferrocyanide electron transfer occurs through an inner sphere system, which requires strong interaction with the electrode surface. However, the attached layer is composed of grafted imidazolium and labile anion, and thus the latter could be exchanged by the ferrocyanide anion and as consequence promote the 2D- electron transfer. Similar result has been reported when investigating the SECM response on ferrocene head-groups attached onto silicon substrate [30]. Combining the SECM investigations with $\mathrm{Fc}$ and ferrocyanide suggests that the electrostatic interactions are responsible for the variation in the shape of the approach curves. Overall, the SECM results confirm the ionic layer grafting and that the layer acts as barrier against electron transfer for positively charged redox molecules while it behaves as transparent for negatively charged redox molecules.

The SECM investigations were further examined on GC/IL/Pt surface. Contrarily to the results observed on GC/IL, the Fc redox probe exhibits current increase and faster electron transfer rate constant about $2 \times 10^{-2} \mathrm{~cm} \cdot \mathrm{s}^{-1}$ (blue curve) while the ferrocyanide redox probe shows a current decreases with an electron 
transfer rate constant value close to $10^{-3} \mathrm{~cm} \cdot \mathrm{s}^{-1}$ (pink curve). This change is probably related to the presence of Pt on top of the ionic layer which changes the electrochemical properties of the electrode interface. Thus the Fc is generated at the electrodeposited Pt onto GC/IL while the ferrocyanide is generated at lower rate due to its inner sphere character. Similar results were obtained when investigating GC/IL/Pd electrodes demonstrating that the observed change in the approach curves are not related to the deposited metal nature.

\subsection{Electrochemical investigations of HER activity}

In the following, the electrocatalytic performances of the generated GC/IL/metal NP towards the hydrogen evolution reaction (HER) were investigated. In this part, Pt or Pd electrochemical deposition onto GC/IL was performed by chrnoamperometry at a potential $-0.4 \mathrm{~V}$ vs $\mathrm{Ag} / \mathrm{AgCl}$.

Figure 4a shows the HER polarization curve of GC/IL/Pt recorded in an acidic medium $\left(0.5 \mathrm{M} \mathrm{H}_{2} \mathrm{SO}_{4}\right)$, under argon atmosphere at a scan rate of $5 \mathrm{mV} / \mathrm{s}$. For comparison, Pt electrodeposited onto GC $(\mathrm{GC} / \mathrm{Pt})$ and commercial $\mathrm{Pt} / \mathrm{C}(\mathrm{GC} / \mathrm{Pt} / \mathrm{C})$ were also investigated. One has to note that except for the commercial $\mathrm{Pt} / \mathrm{C}$ where Nafion is used for the ink preparation, the other investigated electrodes were used as-prepared.
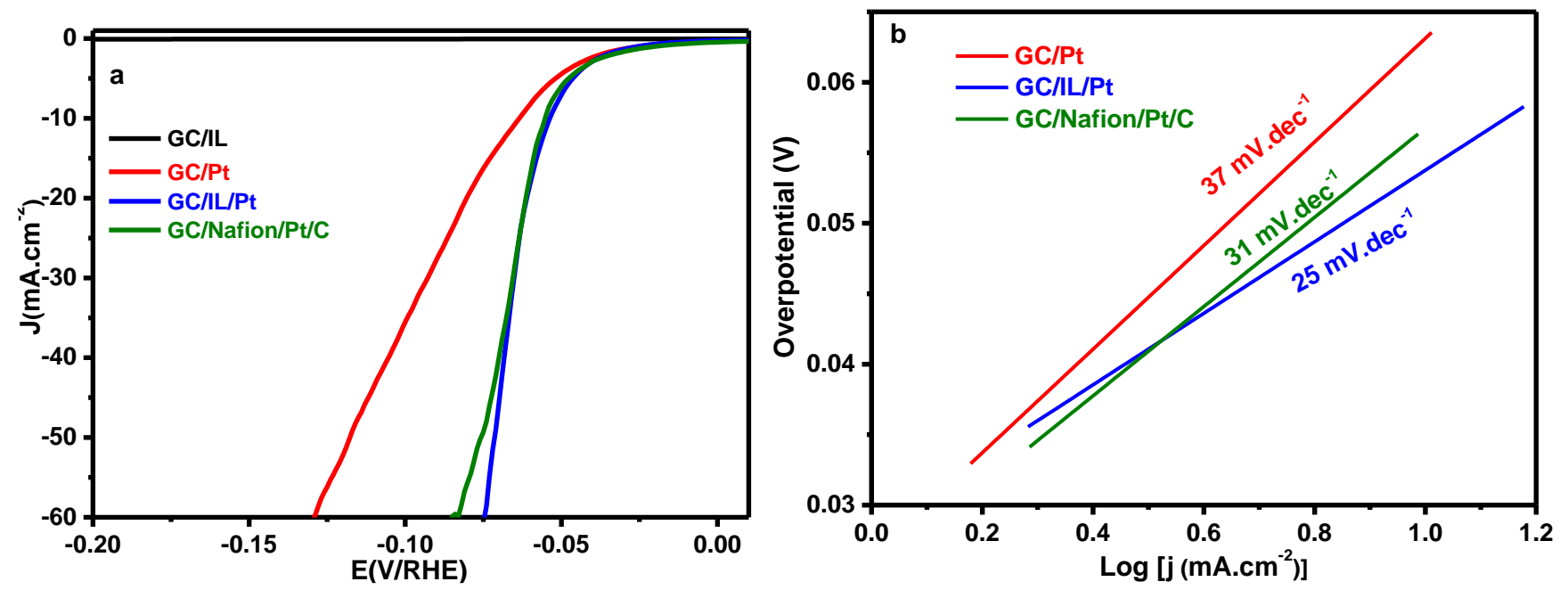

Fig. 4. a) HER polarization curve (LSV) of the GC/IL, GC/Pt, GC/IL/Pt and commercial Pt/C labelled GC/Nafion/Pt/C recorded at $5 \mathrm{mV} . \mathrm{s}^{-1}$ in $0.5 \mathrm{M} \mathrm{H}_{2} \mathrm{SO}_{4}$ aqueous solution. b) The corresponding Tafel plots obtained from polarization curves. 
Figure 4a displays that all the generated electrodes exhibit a pronounced catalytic activity towards HER when compared to GC/IL. Deeper analysis shows that the onset potentials for GC/Pt and GC/IL/Pt are comparable and their values are about $-10 \mathrm{mV}$, which is similar to commercial $\mathrm{Pt} / \mathrm{C}$. In addition, the required overpotential to achieve a current density of $-10 \mathrm{~mA} \cdot \mathrm{cm}^{-2}$ is $65 \mathrm{mV}$ on the GC/Pt, while a lower value of $52 \mathrm{mV}$ is observed for GC/IL/Pt, which is comparable to that obtained on commercial $\mathrm{Pt} / \mathrm{C}$ sample $(55 \mathrm{mV})$. Interestingly, at higher current density $\left(-60 \mathrm{~mA} \cdot \mathrm{cm}^{-2}\right)$, the required over potential on $\mathrm{GC} / \mathrm{IL} / \mathrm{Pt}$ is $74 \mathrm{mV}$, while $84 \mathrm{mV}$ and $130 \mathrm{mV}$ are required on commercial Pt/C and GC/Pt, respectively. The HER is a typical example of two electron transfer reaction with an intermediate $\left(\mathrm{H}_{\mathrm{ads}}\right)$ and can follow two pathways, either the Volmer - Heyrovsky or the Volmer-Tafel mechanism [31]. Tafel slope investigation have been used to compare the reaction rate and the mechanism (Fig. 4b). Tafel slope value of the GC/IL/Pt is about $25 \mathrm{mV} \cdot \mathrm{dec}^{-1}$ which is lower than that of GC/Pt and commercial Pt/C (37 mV.dec ${ }^{-1}$ and $31 \mathrm{mV} \cdot \mathrm{dec}^{-1}$, respectively). This result suggests that the GC/IL/Pt displays the best HER kinetics and that the HER follow a Volmer-Tafel mechanism and that the recombination of two $\mathrm{H}_{\text {ads }}$ is the rate determining step. Overall, the electrocatalytic investigations suggest that the grafted ionic layer enhances the HER performance of the electrodeposited Pt. This behavior demonstrates a synergetic effect between the Pt and the ionic layer. The latter could be linked to the role of the ionic liquid layer during the electrochemical growth of $\mathrm{Pt}$ and to the presence of nitrogen (within the imidazolium, electron-rich dopant), which may facilitate the electron transfer and or affect the $\mathrm{H}_{\text {ads }}$.

Although an improvement of the Pt catalytic activity through the presence of the ionic layer has been confirmed, it is difficult to assess this increase. For this reason and in order to emphasize the role of the ionic layer, similar experiments were performed using Pd as electrocatalyst. Fig. 5a displays the HER polarization curves of the $\mathrm{GC} / \mathrm{Pd}, \mathrm{GC} / \mathrm{IL} / \mathrm{Pd}$ and commercial Pd NPs (labelled GC/Nafion/Pd $\mathrm{NPs}_{\text {) }}$ as well as the corresponding Tafel plots (Figure 5b). 

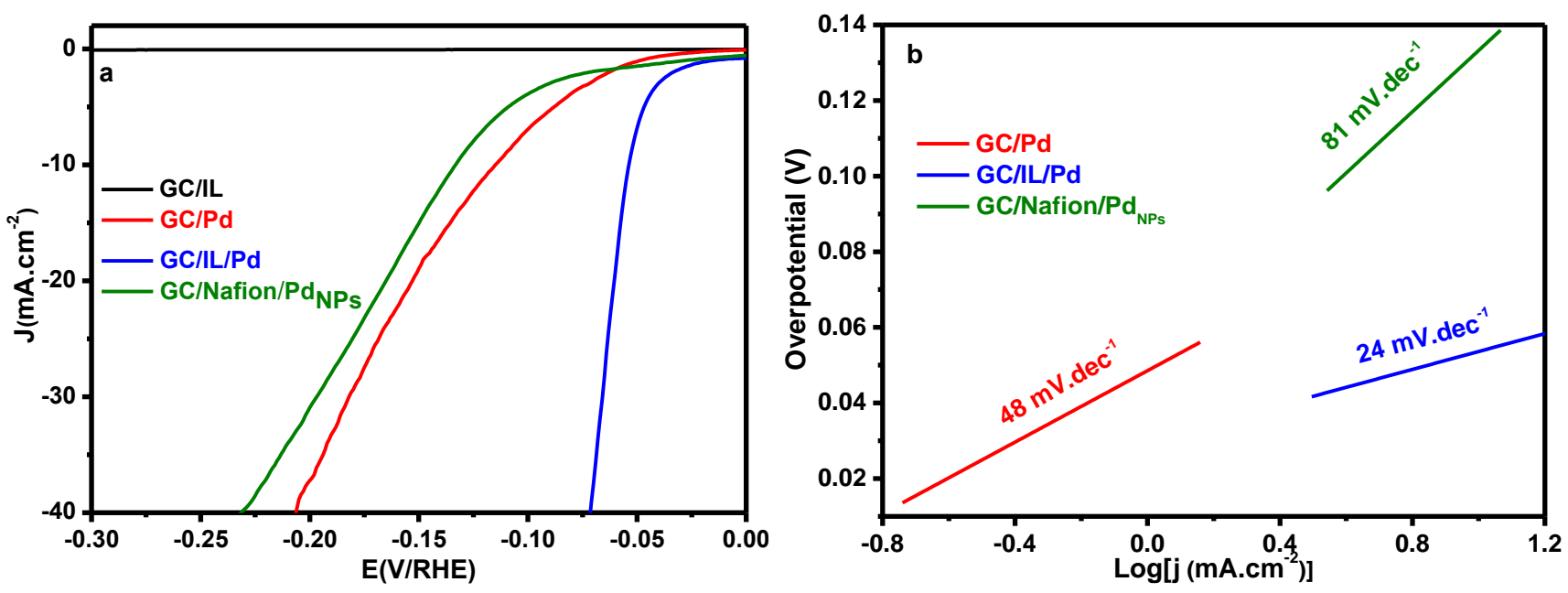

Fig. 5. a) HER polarization curve (LSV) of the GC/IL, GC/Pd, GC/IL/Pd and commercial Pd (labelled $\mathrm{GC} / \mathrm{Nafion} / \mathrm{Pd}_{\mathrm{NPs}}$ ) recorded at $5 \mathrm{mV} . \mathrm{s}^{-1}$ in $0.5 \mathrm{M} \mathrm{H}_{2} \mathrm{SO}_{4}$ aqueous solution. b) The corresponding Tafel plots obtained from polarization curves.

The GC/IL/Pd exhibits the best HER performance with a low onset potential (- $10 \mathrm{mV})$ and low overpotential $(53 \mathrm{mV})$ to reach a current density of $-10 \mathrm{~mA} \cdot \mathrm{cm}^{-2}$, which is lower than those of GC/Pd $(114 \mathrm{mV})$ and $\mathrm{GC} / \mathrm{Nafion} / \mathrm{Pd}_{\mathrm{NPs}}(133 \mathrm{mV})$. The GC/IL/Pd displays electrocatalytic performances similar to that recorded on commercial Pt/C. This was also confirmed by Tafel plots (Fig. 5b). Indeed, the GC/IL/Pd exhibits a Tafel slope of $24 \mathrm{mV} \cdot \mathrm{dec}^{-1}$, which is lower than that of $\mathrm{GC} / \mathrm{Nafion} / \mathrm{Pd}_{\mathrm{NPs}}\left(81 \mathrm{mV} \cdot \mathrm{dec}^{-1}\right)$ and GC/Pd $\left(48 \mathrm{mV} \cdot \mathrm{dec}^{-1}\right)$. More interestingly, the Tafel slope of the GC/IL/Pd is even lower than that of commercial $\mathrm{Pt} / \mathrm{C}\left(31 \mathrm{mV} \cdot \mathrm{dec}^{-1}\right)$ and similar to that observed with GC/IL/Pt $\left(25 \mathrm{mV} \cdot \mathrm{dec}^{-1}\right)$. This value indicates that the HER on GC/IL/Pd occurs through a Volmer-Tafel mechanism with Tafel reaction as the rate determining step. Besides that, the electrochemical impedance spectroscopy (EIS) measurements confirm the superior performance of $\mathrm{GC} / \mathrm{IL} / \mathrm{Pt}$ and $\mathrm{GC} / \mathrm{IL} / \mathrm{Pd}$ as attested by the lower charge transfer resistance (30 and $20 \Omega$, respectively). Overall, these results clearly confirms the dual role of the attached ionic layer, which acts as a binder for the Pd electrocatalyst and also enhances the HER performance and kinetics.

\section{Conclusions}


In summary, this work demonstrates the electrochemical grafting of ionic layer bearing imidazolium moieties onto glassy carbon electrode and its further functionalization through electrochemical deposition of metallic nanoparticles (Pt and Pd). The local electrochemical investigations using SECM suggests that the electrostatic interaction is responsible for the variation of the approach curves response. Indeed, the ionic layer acts as barrier against the electron transfer for positively charged redox molecules, while it behaves as transparent for negatively charged redox molecules. This tendency is reversed when metallic nanoparticles are electrochemically deposited on top of the ionic layer. In addition, the electrolytic activities towards HER of the generated modified electrodes confirm that the HER activity and kinetic on Pt and Pd nanoparticles are enhanced in the presence of the ionic layer. More interestingly, the GC/IL/Pd exhibits excellent HER performances superior to that of commercial $\mathrm{Pt} / \mathrm{C}$. This enhancement is related to the dual role of the attached ionic layer, which acts as a host-guest platform for the electrocatalyst and also to the synergetic effect between the ionic layer and the NP's. The use of thin ionic layer as a host guest platform of metallic NP's is a promising route to generate polymer binder free electrocatalyst and to enhance the intrinsic electrocatalytic performances of a given catalyst.

\section{Declaration of Competing Interest}

The authors declare no conflict of interest.

\section{Acknowledgements}

The authors thank the program Profas B+ and PHC-Tassili for financial support (project $\mathrm{N}^{\circ}$ 46039YC). The authors thank Dr. Philippe Decorse for performing the XPS measurements and for the valuable discussions. 


\section{References}

[1] S. Clair, D. G. de Oteyza, Controlling a Chemical Coupling Reaction on a Surface: Tools and Strategies for On-Surface Synthesis, Chem. Rev. 119 (2019) 4717-4776.

[2] D. Bélanger, J. Pinson, Electrografting: a powerful method for surface modification, Chem. Soc. Rev. 40 (2011) 3995-4048.

[3] J. Pinson, F. Podvorica, Attachment of organic layers to conductive or semiconductive surfaces by reduction of diazonium salts, Chem. Soc. Rev. 34 (2005) 429-439.

[4] B.D. Assresahegn, T. Brousse, D. Bélanger, Advances on the use of diazonium chemistry for functionalization of materials used in energy storage systems, Carbon 92 (2015) 362-381.

[5] D. Xiang, X. Wang, C. Jia, T. Lee, X. Guo, Molecular-scale electronics: from concept to function, Chem. Rev. 116 (2016) 4318-4440.

[6] H. Randriamahazaka, J. Ghilane, Electrografting and controlled surface functionalization of carbon based surfaces for electroanalysis, Electroanalysis 28 (2016) 13-26.

[7] S.K. Singh, A.W. Savoy, Ionic liquids synthesis and applications: An overview, J. Mol. Liq. 297 (2020) 112038

[8] H. Li, P.S. Bhadury, B. Song, S. Yang, Immobilized functional ionic liquids: efficient, green, and reusable catalysts, RSC Adv., 2 (2012) 12525-12551

[9] M.Opallo, A. Lesniewski, A review on electrodes modified with ionic liquids, J. Electroanal. Chem. 656 (2011) 2-16.

[10] M. Watanabe, M.L. Thomas, S. Zhang, K. Ueno, T. Yasuda, K. Dokko, Application of ionic liquids to energy storage and conversion materials and devices, Chem. Rev. 117 (2017) 7190-7239.

[11] B. Xin, J. Hao, Imidazolium-based ionic liquids grafted on solid surfaces, Chem. Soc. Rev. 43 (2014) 7171-7187.

[12] T.N. Pham Truong, H. Randriamahazaka, J. Ghilane, Polymer brushes ionic liquid as a catalyst for oxygen reduction and oxygen evolution reactions, ACS Catal. 8 (2018) 869-875.

[13] D. Mecerreyes, Polymeric ionic liquids: Broadening the properties and applications of polyelectrolytes, Prog. Poly. Sci. 2011 (36) 1629-1648.

[14] S. Bouden, M. Gómez-Mingot, H. Randriamahazaka, J. Ghilane, Surface initiated immobilization of molecules contained in an ionic liquid framework. Anal. Chem. 88 (2016) 1017-1021.

[15] V. Bui-Thi-Tuyet, G. Trippé-Allard, J. Ghilane, H. Randriamahazaka, Surface and electrochemical properties of polymer brush-based redox poly (ionic liquid), ACS appl. Mater. Interf. 8 (2016) 2831628324.

[16] M. Gómez-Mingot, V.B. Thi-Tuyet, G. Trippé-Allard, J. Ghilane, H. Randriamahazaka, Oxidative grafting of a redox-molecule-based ionic liquid onto an electrode surface: anion exchange within a layer, ChemElectroChem. 1 (2014) 1467-1470.

[17] J. Ghilane, G. Trippe-Allard, J.C. Lacroix, Grafting of imidazolium ion-terminated layer using electrochemical reduction of diazonium: redox active counter anion exchange within the layer, Electrochem. Commun. 27 (2013) 73-76.

18 S. Bouden, G. Trippé-Allard, J. Ghilane, H. Randriamahazaka Electrochemical immobilization of redox active molecule based ionic liquid, Electrochem. Commun. 58 (2015) 65-68

[19] V. Bui-Thi-Tuyet, G. Trippé-Allard, J. Ghilane, H. Randriamahazaka Surface functionalization of ferrocene based ionic liquid onto carbon surface using stepwise grafting, J. Electroanal. Chem. 713 (2014) $28-31$ 
[20] C. Gautier, I. López, T. Breton, A post-functionalization toolbox for diazonium (electro)-grafted surfaces: review of the coupling methods, Mater. Adv. 2 (2021) 2773-2810

[21] J. Ghilane, J.C. Lacroix, Formation of a bifunctional redox system using electrochemical reduction of platinum in ferrocene based ionic liquid and its reactivity with aryldiazonium, J. Am. Chem. Soc. 135 (2013) 4722-4728.

[22] J. Ghilane, F. Hauquier, J.C. Lacroix, Oxidative and stepwise grafting of dopamine inner-sphere redox couple onto electrode material: electron transfer activation of dopamine, Anal. Chem. 85 (2013) $11593-11601$

[23] R. Toyoshima, T. Tanaka, T. Kato, K. Uchida, H. Kondoh, In situ AP-XPS analysis of a Pt thin-film sensor for highly sensitive H2 detection, Chem. Commun. 56 (2020) 10147-10150.

[24] S. Pacanowski, M. Wachowiak. B. Jabłonski. B. Szymanski. L. Smardz, Interface mixing and hydrogen absorption in $\mathrm{Pd} / \mathrm{Mg}$ and $\mathrm{Pd} / \mathrm{Al} / \mathrm{Mg}$ thin films, Int. J. Hydrogen Energy 46 (2021) 806-813

[25] T. N. Pham-Truong, B. Deng, Z. Liu, H. Randriamahazaka, J. Ghilane, Local electrochemical reactivity of single layer graphene deposited on flexible and transparent plastic film using scanning electrochemical microscopy, Carbon 130 (2018) 566-573.

[26] J. Ghilane, M. Guilloux-Viry, C. Lagrost, J. Simonet, P. Hapiot, Reactivity of platinum metal with organic radical anions from metal to negative oxidation states, J. Am. Chem. Soc. 129 (2007) 6654-6661. [27] S. Amemiya, R. Chen, N. Nioradze, J. Kim, Scanning electrochemical microscopy of carbon nanomaterials and graphite, Acc. Chem. Res. 49 (2016) 2007-2014.

[28] S.Y. Ku, K.T. Wong, A.J. Bard, Surface patterning with fluorescent molecules using click chemistry directed by scanning electrochemical microscopy, J. Am. Chem. Soc. 130 (2008) 2392-2393.

[29] J. Kwak, A.J. Bard, Scanning electrochemical microscopy. Theory of the feedback mode, Anal. Chem. 61 (1989) 1221-1227.

[30] F. Hauquier, J. Ghilane, B. Fabre, P. Hapiot, Conducting ferrocene monolayers on nonconducting surfaces, J. Am. Chem. Soc. 130 (2008) 2748-2749.

[31] N. Dubouis, A. Grimaud, The hydrogen evolution reaction: from material to interfacial descriptors, Chem. Sci. 10 (2019) 9165-9181. 